\title{
A Study on the Care Experience of the Elderly with Dementia and the Quality of Life of the Family
}

\author{
Mi-Ran Lee1)
}

\begin{abstract}
This research was conducted to provide basic materials for supporting family members of senile dementia patients, and supplementing social service as well as welfare policy for the elderly based on actual burden and experience of family members caring senile dementia patients at home. The subjects of this research were 11 family members who took care of senile dementia patients for more than six months using purposive sampling through Elderly Home Care Facility and Day Care Center for the Elderly. Qualitative content analysis was used based on one-on-one in-depth interviews. As a result, more than half of the subjects were low-income group, high-aged class with diseases and wives were the main care providers. The analyzed categories were 13 sub-themes induced by 7 topic bundles and 3 ultimate themes. The results indicate that customized life support services and development of professional personnel are required for the senile dementia patients and their family members and 24/7 extensive local centers for dementia should be established urgently. In this sense, convergent and practical support is required by taking into account diverse fields to create environment for improving recognition on dementia, activation of elderly-friendly dementia caring industry based on fourth industrial revolution, etc.
\end{abstract}

Keywords : Dementia, Caring, Elderly-Friendly, Convergent, Fourth Industrial Revolution

\section{Introduction}

The life expectancy of Koreans this year, 2017, is 82.2 years old according to the World Economic Forum report[1], which has increased by about 10 years compared to 20 years ago. The population over the age of 100 is 3,500 which has nearly doubled in the last five years, and by 2030 it is expected to be 10,000. Korea will become an aged society when the proportion of the population over 65 years old exceeds $14 \%$ of the total population next year, and it will be super aged society when it's over $20 \%$ in 2025. Although the pace of aging in Korea has progressed fast compared to other developed countries, many of the requirements for accepting it are insufficient in various fields, and the arrival of aged society is expected to have various social problems. In addition to personal

Received(December 29, 2017), Review Result(1st: January 15, 2018, 2nd: February 14, 2018), Accepted(February 23, 2018)

1) (Professor) Dept. Social Welfare, Kosin Univ., 194 Wachi-Ro Yeongdo-Gu, Busan, Korea email: dsmr0815@kosin.ac.kr 
problems such as economic poverty, health-medical problems, boredom·dullness, alienation from society, nationally there are problems of support and protection, decrease of economic vitality due to decrease of the producible population, increase of social security costs including medical care and pension due to the increase of the elderly population rate[2].

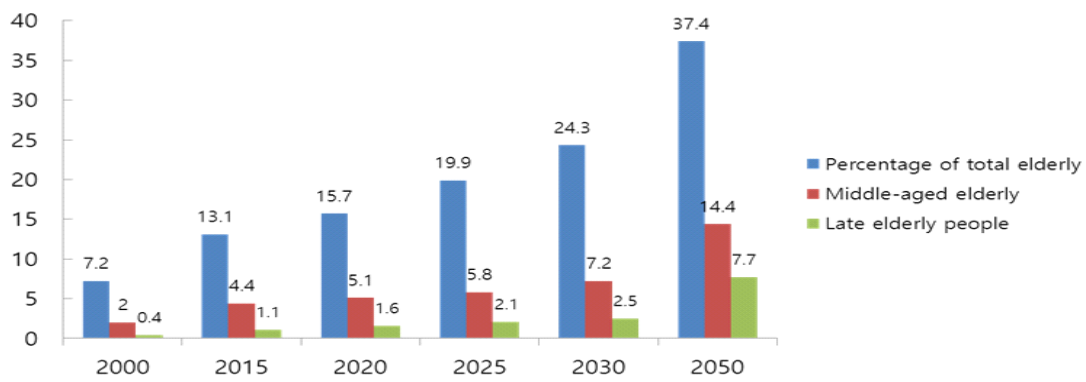

[Fig. 1] Population Size and Structure Change (source: Statistical Office)

Dementia, one of the chronic diseases of the elderly, is continuously growing worldwide, and it is expected to reach 74.7 million in 2030 and 131.5 million in 2050[3]. In Korea, the number of demented elderly patients aged 65 or older is estimated to reach about 650,000 in 2015, a prevalence rate of $9.8 \%$. It is estimated to increase to $10.4 \%$ in 2020 and $15.1 \%$ in 2050[4]. In other words, dementia patients, the geriatric diseases, are rapidly increasing with aging. The increase in the number of patients with dementia means an increase in social costs caused by dementia. The average annual increase in dementia patients is $10.1 \%$, and the long-term medical care costs of dementia patients increased by an annual average of $15.5 \%$. It accounted for about $1.0 \%$ of the gross domestic product, 11.7 trillion won in 2013, and it is estimated that it will increase to about $1.5 \%$ of the gross domestic product, 43.2 trillion won by 2050[5].

[Table 1] Social Cost of Dementia

Unit : trillion won, \%

\begin{tabular}{|c|c|c|c|c|c|c|}
\hline \multicolumn{2}{|c|}{ Classification } & 2,013 & 2,020 & 2,030 & 2,040 & 2,050 \\
\hline \multicolumn{2}{|c|}{ Real GDP C } & $1,134.9$ & $1,471.3$ & $1,938.6$ & $2,384.7$ & $2,787.8$ \\
\hline \multirow{2}{*}{$\begin{array}{c}\text { Social cost of } \\
\text { dementia }\end{array}$} & Actual Cost D & 11.7 & 15.2 & 23.1 & 34.2 & 43.2 \\
\cline { 2 - 7 } & $\begin{array}{c}\text { Percentage of GDP } \\
\text { D/C }\end{array}$ & 1.0 & 1.0 & 1.2 & 1.4 & 1.5 \\
\hline
\end{tabular}

(source: National Assembly Budget Office) 
Therefore, it is necessary to take measures to reduce socioeconomic costs due to the burden of care for the family, as well as the direct medical care and medical treatment costs of demented patients. Dementia is a cognitive disorder that progressively reduces the ability of human functions and independence of performing their daily activities at unpredictable levels[6]. In addition, the quality of life of the family is deteriorated and the cost and burden for the treatment and care of the dementia patients are directly linked to increased number of patients with dementia. In addition, the increase in the prevalent population of patients with dementia. As this has been recognized as a socioeconomically serious problem, studies have been actively conducted. Dementia is not a mere illness, but it affects all aspects of daily life and social life by reducing overall quality of life. It is a disease that requires family responsibility and national responsibility. Clinical manifestations of dementia range from short-term memory impairment to severe cerebral dysfunction, resulting in a decrease in the quality of life of family members as well as functional impairment of patients[7]. In Korea, $72 \%$ of dementia patients are taken care of by their families[8], and the care giving family has to cope with mental, social, and financial burdens as well as their physical burdens. Their overall life changes and difficulties are known to be diverse and serious. In addition, depression and suicidal tendencies of the elderly with dementia are higher than those of the general elderly, and the depression of the family with demented elderly is also pointed out as a serious problem implying suicide risk due to lower quality of life[9].

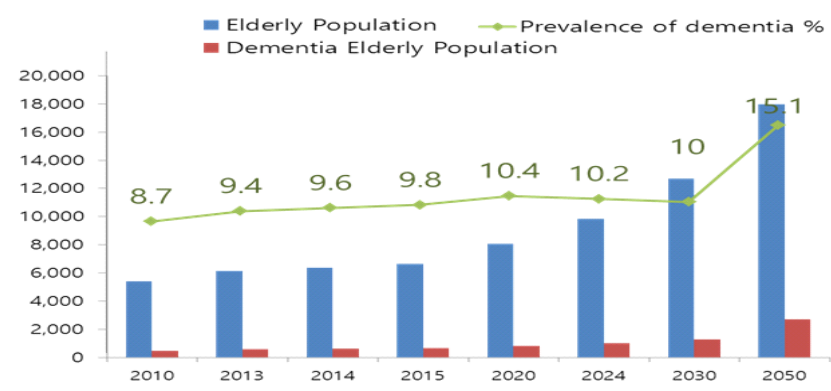

[Fig. 2] Dementia Prevalence Survey(source: Ministry of Health and Welfare)

However, among the demented elderly, only $29.6 \%$ are admitted to medical facilities to receive medical care and most of the elderly with dementia are taken care at home[10]. Thus, the role of the caregiver for the demented elderly at the home is very important. The primary caregiver is a person who lives with the demented elderly person and is responsible for the care of the elderly in the process of caring, and primarily protects and supervises the elderly. In Korea, 9 out of 10 caregivers 
of the demented elderly are family members and they provide care according to the condition of the demented elderly[11]. However, they take care of the elderly with dementia with lack of educational support for the knowledge of how to take care of dementia patients, as well as the ethological knowledge of dementia. The misinformation about dementia deepens the severity of dementia. On the other hand, accurate knowledge of dementia can slow the progression of dementia, so the primary caregiver's knowledge of dementia is essential in caring for the demented elderly. In addition, primary caregivers feel a considerable burden of care in the physical, mental, and financial aspects as the effort and time to care for the demented elderly increase due to the problematic behaviors and dependence of the demented elderly. These burdens of care are the main factors that exhaust the caregiver, such as depression, suicidal tendency, etc., which adversely affect the primary caregiver and care giving quality oHowever, considering that the experience of the family caring for the demented elderly is not only continuously changing according to the socio-cultural situation but also is a complex and subjective phenomenon in which various factors are intertwined and potentially influence each other, the research on the care of dementia by family is still very limited in Korea. In particular, since the caring experience is difficult to conceptualize and is difficult to measure easily, in-depth research is needed to approach it from various perspectives with various data[12].

Despite the serious problems of support for the demented elderly and their families, the management of dementia and the establishment of social infrastructure for a care giving family are still insufficient. As stated above, dementia is a chronic disease that requires continuous and long-term treatment and management causing a complex physical, psychological and economic problem for patients, families and society as a whole. Since the 1990s, Korea has begun to pay attention to dementia as a chronic disease of the elderly due to aging and a national policy was set up to detect and treat high-risk groups early and improve the quality of life of demented elderly and their families and reduce the burden of care. The Long-Term Care Insurance for the Aged has been implemented since 2007. According to the Dementia Control Act (2012.8) enacted as part of the 1st comprehensive dementia prevention policy in 2008, a basic framework for treating and managing dementia has been established, but support for the elderly with dementia remains a mere protection measure and it is still insufficient when it comes to practical support reflecting family needs[13]. Thus, it is time to develop and support quality services for the demented elderly and their families. Therefore, the purpose of this study is to analyze various in-depth experiences through direct care process for the main care giving family caring for the demented elderly and to examine the impact of family members on the quality of life to provide basic data on the development of practical social services for demented elderly and their care giving family and effective policy alternatives. 


\section{Research Method \& Results}

Qualitative research method was used for this study based on one-on-one interviews for in-depth understanding based on actual care experience as the primary care giving family member of the elderly with dementia. The qualitative research approach helps to understand specific experience as a whole by providing deep and vivid information about the phenomenon[14].

For participants, the primary care giving family who has taken care of the demented elderly living together for more than 6 month were selected through the elderly welfare center and the care center using an intentional sampling method. All interviews were conducted in semi-structured form and the subjects were consisted of voluntary participants who agreed to the purpose of this study in writing. In-depth interviews were conducted from August 10 to September 15, 2017 at the participant's house or welfare center counseling rooms and took an average of 1 to 2 hours. Additional questions and interviews for data analysis were performed from home visits or telephone interviews for supplement the data collection.

The interviews conducted at the home of the participants due to the time and distance revealed the health and functional status of the elderly with dementia, the care environment, and the financial situation. A rich data was collected in some cases where home care workers or other family members and friends worked at the time of the visit providing additional explanations for the situation of the demented elderly and caregivers. In-depth interviews took about 60 minutes on average, but some cases took more than two hours. The in-depth interviews were recorded under the consent of the participants and were documented by the researcher on a case-by-case basis. Some participants also complained about the frustration and difficulty of caring for a long time at the in-depth interviews. The present was given to the participants as an appreciation of their time and information they provided.

The analysis of the data was done by continuous comparison analysis according to the categorical content analysis. The meaning units were coded through the repeated reading of the data, and the sub themes were extracted by comparing the concepts and main themes and final themes were analysed.

The survey was conducted by direct interview with participants by the researcher. Before the interviews, the purpose and method of the study, the volunteerism of the participant and the right to discontinue the study, anonymity for confidentiality and the recording of the interview were explained to the participants and written consents were obtained. 
[Table 2] Characteristics of Participants

\begin{tabular}{|c|c|c|c|c|c|c|}
\hline Id & $\begin{array}{r}\text { Family } \\
\text { status }\end{array}$ & Age & $\begin{array}{c}\text { Education } \\
\text { background }\end{array}$ & Health conditions & $\begin{array}{r}\text { Years of } \\
\text { caregiving }\end{array}$ & $\begin{array}{l}\text { Economic } \\
\text { status }\end{array}$ \\
\hline 1 & \multirow{7}{*}{ Wife } & 66 & $\begin{array}{l}\text { Middle school } \\
\text { graduate }\end{array}$ & $\begin{array}{l}\text { Stress and headache } \\
\text { physical burden }\end{array}$ & 10 & Middle \\
\hline 2 & & 69 & $\begin{array}{l}\text { Middle school } \\
\text { graduate }\end{array}$ & Had surgery for legs & 4 & Middle \\
\hline 3 & & 70 & $\begin{array}{c}\text { Elementary } \\
\text { school graduate }\end{array}$ & $\begin{array}{l}\text { Very bad, diabetes, } \\
\text { blood pressure problem }\end{array}$ & 3 & Low \\
\hline 4 & & 71 & $\begin{array}{l}\text { Middle school } \\
\text { graduate }\end{array}$ & $\begin{array}{c}\text { Thyroid problems, arthritis } \\
\text { physical burden }\end{array}$ & 5 & Low \\
\hline 5 & & 74 & $\begin{array}{c}\text { Elementary } \\
\text { school drop out }\end{array}$ & Arthritis, hyperlipemia & 7 & Low \\
\hline 6 & & 65 & Bachelor's degree & $\begin{array}{c}\text { Had surgery for legs, } \\
\text { heart problems }\end{array}$ & 5 & Middle \\
\hline 7 & & 82 & $\begin{array}{c}\text { Elementary } \\
\text { school drop out }\end{array}$ & $\begin{array}{c}\text { Stress, } \\
\text { High blood pressure }\end{array}$ & 6 & Low \\
\hline 8 & \multirow[t]{2}{*}{ Husband } & 68 & $\begin{array}{l}\text { Middle school } \\
\text { graduate }\end{array}$ & Stress, diabetes & 3 & Low \\
\hline 9 & & 72 & $\begin{array}{l}\text { High school } \\
\text { graduate }\end{array}$ & $\begin{array}{l}\text { Diabetes, headache } \\
\text { hyperlipemia }\end{array}$ & 2 & Low \\
\hline 10 & Daughter & 58 & $\begin{array}{l}\text { Middle school } \\
\text { graduate }\end{array}$ & $\begin{array}{c}\text { Severe stress, arthritis, } \\
\text { depression }\end{array}$ & 3 & Low \\
\hline 11 & $\begin{array}{l}\text { Daughter } \\
\text {-in-law }\end{array}$ & 56 & $\begin{array}{l}\text { Middle school } \\
\text { graduate }\end{array}$ & $\begin{array}{c}\text { Physical burden, arthritis, } \\
\text { heart problem }\end{array}$ & 2 & Middle \\
\hline
\end{tabular}

[Table 3] Analytic Themes of Findings

\begin{tabular}{|c|c|c|}
\hline Sub themes & Main themes & Final themes \\
\hline $\begin{array}{l}\text { 1. Feel sorry and pitiful } \\
\text { 2. It's hard to accept, I do not know what to do. }\end{array}$ & Ambivalence & \multirow{3}{*}{ Overall exhaustion } \\
\hline $\begin{array}{l}\text { 3. Family discord due to demented elderly. } \\
\text { 4. Painful to care for parents who were supporters. } \\
\text { 5. Do extreme thoughts like suicide. }\end{array}$ & Psychological pain & \\
\hline $\begin{array}{l}\text { 6. Difficulty due to not knowing how to cope with dementia } \\
\text { 7. Physical fatigue due to endless anxious behavior. }\end{array}$ & Physical fatigue & \\
\hline $\begin{array}{l}\text { 8. Try to find a way to relieve stress. } \\
\text { 9. Try to find support for the dementia family }\end{array}$ & Efforts to overcome & \multirow[t]{2}{*}{ Empty the mind } \\
\hline 10. Alienated life by giving up leisure and gathering. & Alienated life & \\
\hline
\end{tabular}


12. Pray and read the Bible when facing spiritual suffering. 13. Go to church or temple to get support and information.

\section{Conclusion and Suggestions}

As the incidence of senile dementia rapidly increases with age, dementia patients progress more rapidly than the aging population, so the elderly population will increase by $60 \%$ after 10 years, but the dementia population will increase by 77\%. It is expected to exceed 1 million by 2025 and increase almost twice every 20 years[4]. The estimated social cost of dementia is 11.7 trillion won (2013), which is an enormous amount of personal and socioeconomic burden, and this cost is expected to double every 10 years[5].

The purpose of this study was to provide basic data for the support of dementia families, social service development, and elderly welfare policy supplements through examining the caregiving burden and practical experience of family members who care for the demented elderly at home. The subjects of this study were 11 primary caregivers who have taken care of demented elderly while living together for more than 6 months collected using the intentional sampling method through the elderly welfare center and the care center. It was analyzed inductively using qualitative content analysis method through the one-on-one in-depth interview. As a result of the analysis, more than half of the subjects were in the low-income class as subjective financial status and the primary caregivers were mainly in an older age group, most of them had more than one disease and the wives were the primary caregivers. The interview data through the care experience of the family members of the demented elderly were categorized into 13 sub themes, the 13 sub themes were composed of 7 main themes, and the final 3 themes were analyzed. In conclusion, it is necessary to strengthen the management of the elderly living alone and the high-risk patients with dementia, and to support the early detection of dementia continuously and to develop content for the prevention of dementia for healthy elderly. The systematic support of the government is requested to improve the living environment for the safety of dementia patients at home and it is urgent to reduce the burden of actual care through socioeconomic support for the family with dementia patients.

According to the prevalence of dementia survey, the risk of dementia is higher for the elderly, for women, depressed, absence of spouse, and lower education. Therefore, in the community, more active 
prevention of dementia should be given priority to those who have these risk factors. In order to improve the effectiveness of community dementia management and preventive programs, more active dementia prevention programs through linkage of local infrastructure and systematic education and promotion of dementia are needed.

Although the knowledge of dementia has been widely available to both primary caregivers of the elderly with dementia as well as the general public thanks to the mass media, the caregivers have a very limited opportunity to receive the education necessary for care for the elderly with dementia. It is necessary to provide a dementia education program suitable for the level of caregivers.

As a result of the interviews, the most burdensome area was the financial burden, but the limit of individual social activities was confirmed. In Korea, for the demented elderly and the primary caregivers, the dementia rating system was implemented starting in 2014 to provide diverse welfare services such as the use of care centers and support for dementia drugs, etc. but the service level felt by the dementia family is insufficient. It is necessary to seek for measures to reduce the burden of primary caregivers by actively promoting and participating in the service in the future.

Therefore, it is predicted that as the period for supporting the elderly with dementia is prolonged, the care quality is decreased due to the increased burden of the primary caregiver. In order to raise the care quality of the primary caregiver, the burden of care should be reduced. To this end, the demented elderly should be provided with adequate care to delay the progression of dementia. In the primary caregiver aspect, the coping and caring methods should be taught for problematic behaviors and cognitive dysfunction of the elderly with dementia.

The family support for the elderly is weakened, and the capacity of the family to cope with the care of the demented elderly is becoming vulnerable. Rapid aging trends vary widely depending on the industrial structure and demographic structure of each community even in the same local government. Therefore, the local governments should closely analyze the changes in the aging population structure in the area closely related to life welfare to establish long-term countermeasures. To effectively manage dementia, it is necessary to analyze community resources as providers of dementia prevention and treatment programs, and seek ways to link infrastructure to the agencies responsible for each business content. Systematic and specific efforts will be needed through consultation between the public and private sectors of the community in order to be a viable linkage for improvement in the efficiency of the prevention and management of dementia in the community. Effective dementia prevention projects will reduce the anticipated massive social cost burden. The increase in the aging population is accelerating an increase in dementia care management. It is necessary to establish an infrastructure for effective prevention of dementia by mobilization community resources because the current delivery system is limited in covering the generation of 
baby boomers.

Therefore, it is imperative to establish customized financial and leisure life support services and nurturing professional manpower for crisis intervention support for primary caregivers as well as a local dementia support centers operating 24 hours, 365 days for night and weekend services to continue and comprehensive support without discrimination between rural or urban area. In order to achieve this goal, complex and practical support is required such as 'activation of aged-friendly dementia care industry through the 4th industrial revolution' in response to 'dementia awareness improvement education', 'environment for early prevention of dementia' and the change in the times using various fields.

\section{References}

[1] OECD data. https://data.oecd.org/healthstat/life-expectancy-at-birth.htm, December 29, (2017)

[2] M. R. Lee, Effect of Exercise Prescription Service Customized for the Elderly in Community, International Journal of Bio-Science and Bio-Technology, (2016), Vol.8, No.3, pp.85-100.

[3] World Alzheimer's Report, London, Alzheimer's Disease International, (2015), pp.22-23.

[4] Ministry of Health and Welfare, The establishment of a comprehensive plan for dementia management (2016 $\sim$ 2020), (2015)

[5] National Assembly Budget Office, 2014-2060 Long-Term Financial Outlook Report, http://www.nabo.go.kr/Sub/01Report/01_01_Board.jsp?funcSUB=view\&arg_id=5301\&bid=19, November 03, (2014)

[6] Amy E. Sanders, James Nininger, John Absher, Amy Bennett, Samantha Shugarman \& Robert Roca., Quality Improvement in Neurology: Dementia Management Quality Measurement Set Update, The American Journal of Psychiatry, (2017), Vol.174, No.5, pp.493-498.

[7] Blackburn R. \& Bradshaw T., Music therapy for service users with dementia: a critical review of the literature, J Psychiatr Ment Health Nurs, (2014), Vol.21, No.10, pp.879-888.

[8] Ministry of Health \& Welfare, National dementia strategy 2013-2015, Retrieved January 3, 2013, from $\mathrm{http} / / /$ www.mw.go.kr/front_new/al/sal0301vw.jsp?PAR_MENU_ID=04\&MENU_ID=0403\&BOARD_ID=140\&BO ARD_FLAG $=00 \& C O N T \_S E Q=274723 \&$ page $=1$, July 30 (2012)

[9] Kim, J. P., \& Hyun, M. Y., Depression and suicidal ideation in elders with dementia, Journal of Korean Academy of Nursing, (2013), Vol.43, No.2, pp.296-303.

[10] Statistics Korea, Management of cancer, dementia or chronic disease: Therapy method and nursing method, Statistics Korea, http://kosis.kr/statHtml/statHtml.do?orgId=217\&tblId=DT_217A2010A00316\&conn_path=I2, December 02 (2014)

[11] Yoon BR, Shim YS, Kim YD, Lee KO, Na SJ, Hong YJ, Who takes care of patients with dementia in 
Korea: A study on the present state of patients with dementia living alone and primary caregivers, Dementia and Neurocognitive Disorders, (2012), Vol.11, No.1, pp.13-17.

[12] M. R. Lee, Plans to Establish a Network of Resources in a Community to Improve Efficiency of a Dementia Preventive Project in Busan Metropolitan City, Advanced Science and Technology Letters, (2016), Vol.131, pp.147-151.

[13] Ministry of Health and Welfare, The second national general plan for dementia management, (2012)

[14] Padgett, D. K., Qualitative Methods in Social Work Research, SAGE publications, (1998) 